\title{
Anti L-Fuzzy M-Cosets of M-Groups
}

\author{
P.Pandiammal \\ Department of Mathematics, \\ PSNA College of Engineering \\ and Technology, \\ Dindigul, Tamil Nadu,
}

\author{
R.Natarajan \\ HOD, Department of Mathematics, \\ Alagappa University, \\ Karaikudi-630 003, Tamil Nadu, \\ India
}

\author{
N.Palaniappan \\ Department of Mathematics, \\ Alagappa University, Karaikudi- \\ 630 003, Tamil Nadu, India
}

\begin{abstract}
This paper contains some definitions and results of anti Lfuzzy M-cosets of a M-group and generalized characteristic anti L-fuzzy M-subgroup of a M-group. Using homomorphism and anti-homomorphism in anti L-fuzzy M-cosets of a M-group is studied. Some properties of anti L-fuzzy M-cosets of a M-group are also established.
\end{abstract}

\section{Keywords:}

L-fuzzy subset, homomorphism, anti-homomorphism, anti L-fuzzy M-subgroup, anti L-fuzzy M-coset, pseudo anti L-fuzzy M-coset, anti L-fuzzy M-Middle coset, generalized characteristic anti L-fuzzy M-subgroup.

\section{INTRODUCTION}

The notion of fuzzy sets was introduced by L.A. Zadeh [10]. Fuzzy set theory has been developed in many directions by many researchers and has evoked great interest among mathematicians working in different fields of mathematics, such as topological spaces, functional analysis, loop, group, ring, near ring, vector spaces, automation. In 1971, Rosenfield [1] introduced the concept of fuzzy subgroup. Motivated by this, many mathematicians started to review various concepts and theorems of abstract algebra in the broader frame work of fuzzy settings. In [2], Biswas introduced the concept of anti- fuzzy subgroups of groups. Palaniappan. $\mathbf{N}$ and Muthuraj, [6] defined the homomorphism, antihomomorphism of a fuzzy and an anti-fuzzy subgroups. In this paper we define a new algebraic structure of anti Lfuzzy M-cosets of a M-group and study some their related properties.

\section{PRELIMINARIES}

1.1 Definition: Let $X$ be a non-empty set and $L=(L, \leq)$ be a lattice with least element 0 and greatest element 1 . A Lfuzzy subset $A$ of $X$ is a function $A: X \rightarrow L$.

1.2 Definition: Let $\mathrm{G}$ be a M-group. A L-fuzzy subset A of $\mathrm{G}$ is said to be anti L-fuzzy M-subgroup (ALFMSG) of G if its satisfies the following axioms:

(i) $\mu_{\mathrm{A}}(\mathrm{mxy}) \leq \mu_{\mathrm{A}}(\mathrm{x}) \vee \mu_{\mathrm{A}}(\mathrm{y})$,

(ii) $\mu_{\mathrm{A}}\left(\mathrm{x}^{-1}\right) \leq \mu_{\mathrm{A}}(\mathrm{x})$, for all $\mathrm{x} \& \mathrm{y}$ in $\mathrm{G}$.
1.3 Definition: Let $A$ and $B$ be two anti L-fuzzy Msubgroups of a M-group $\mathrm{G}$. Then $\mathrm{A}$ and $\mathrm{B}$ are said to be conjugate anti L-fuzzy M-subgroups of $\mathrm{G}$ if for some $\mathrm{g}$ in $\mathrm{G}, \mu_{\mathrm{A}}(\mathrm{x})=\mu_{\mathrm{B}}\left(\mathrm{g}^{-1} \mathrm{xg}\right)$, for every $\mathrm{x}$ in $\mathrm{G}$.

1.4 Definition: Let A be an anti L-fuzzy M-subgroup of a M-group G. For any $a \in \epsilon^{\prime} G$, aA defined by $\left(a \mu_{A}\right)(x)=\mu_{A}($ $\left.a^{-1} x\right)$, for every $x$ in $G$ is called an anti L-fuzzy M-coset of the M-group $\mathrm{G}$.

1.5 Definition: Let A be an anti L-fuzzy M-subgroup of a M-group $\mathrm{G}$ and $\quad \mathrm{H}=\left\{\mathrm{x} \in \mathrm{G} / \mu_{\mathrm{A}}(\mathrm{x})=\right.$ $\left.\mu_{\mathrm{A}}(\mathrm{e})\right\}$, then $\mathrm{O}(\mathrm{A})$, order of $\mathbf{A}$ is defined as $\mathrm{O}(\mathrm{A})=\mathrm{O}(\mathrm{H})$.

1.6 Definition: Let A be an anti L-fuzzy M-subgroup of a M-group $G$. Then for any $a, b \in G$, an anti L- fuzzy Mmiddle coset $\mathrm{aAb}$ of $\mathrm{G}$ is defined by $\left(\mathrm{a} \mu_{\mathrm{A}} \mathrm{b}\right)(\mathrm{x})=\mu_{\mathrm{A}}\left(\mathrm{a}^{-1} \mathrm{x} \mathrm{b}\right.$ ${ }^{1}$ ), for every $x \in G$.

1.7 Definition: Let A be an anti L-fuzzy M-subgroup of a $M$-group $G$ and $a \in G$. Then the pseudo anti L-fuzzy Mcoset $(a A)^{p}$ is defined by $\left(\left(a \mu_{A}\right)^{p}\right)(x)=p(a) \mu_{A}(x)$, for every $\mathrm{x} \in \mathrm{G}$ and for some $\mathrm{p} \in \mathrm{P}$.

1.8 Definition: Let A be a L-fuzzy subset of $X$. For $t \in L$, the lower level subset of $A$ is the set, $A_{t}=\left\{x \in X: \mu_{A}(x) \leq\right.$ $t$ \}.This is called a L-fuzzy lower level subset of $A$.

1.9 Definition : Let $G$ be a M-group. An anti L-fuzzy Msubgroup $A$ of $G$ is said to be anti L-fuzzy normal Msubgroup (ALFNMSG) of G if $\mu_{A}(x y)=\mu_{A}(y x)$, for all $x$ and $\mathrm{y}$ in $\mathrm{G}$.

1.10 Definition: Let $\left(\mathrm{G},\right.$. ) and $\left(\mathrm{G}^{\prime},\right.$. .) be two M-groups. A map $f: G \rightarrow G^{\prime}$ is called M-group isomorphism if the following conditions are satisfied:

(i) $\mathrm{f}$ is a bijection,

(ii) $f(x y)=f(x) f(y)$ for all $x$ and $y$ in $G$.

1.11 Definition: Let $(G,$.$) and \left(G^{\prime},.\right)$ be two M-groups. A map $f: G \rightarrow G^{\prime}$ is called a M-group anti-isomorphism if the following conditions are satisfied:

(i) $\mathrm{f}$ is a bijection,

(ii) $f(x y)=f(y) f(x)$ for all $x$ and $y$ in $G$.

1.12 Definition: An anti L-fuzzy M-subgroup A of a Mgroup $G$ is called a generalized characteristic anti L- 
fuzzy M-subgroup (GCALFMSG) if for all $x$ and $y$ in $G$, $\mathrm{O}(\mathrm{x})=\mathrm{O}(\mathrm{y})$ implies $\mu_{\mathrm{A}}(\mathrm{x})=\mu_{\mathrm{A}}(\mathrm{y})$.

\section{PROPERTIES OF ANTI L-FUZZY M- COSETS}

2.1 Theorem: Let A be an anti L-fuzzy M-subgroup of a finite $\mathrm{M}$-group $\mathrm{G}$, then

$\mathrm{O}(\mathrm{A}) /$

$\mathrm{O}(\mathrm{G})$.

Proof: Let A be an anti L-fuzzy M-subgroup of a finite Mgroup $\mathrm{G}$ with e as its identity element.

Clearly $\mathrm{H}=\left\{\mathrm{x} \in \mathrm{G} / \mu_{\mathrm{A}}(\mathrm{x})=\mu_{\mathrm{A}}(\mathrm{e})\right\}$ is a M-subgroup of the M-group $\mathrm{G}$ for $\mathrm{H}$ is a lower $\mathrm{t}$-level subset of a M-group $\mathrm{G}$ where $\mathrm{t}=\mu_{\mathrm{A}}(\mathrm{e})$.

By Lagranges theorem, $\mathrm{O}(\mathrm{H}) / \mathrm{O}(\mathrm{G})$.

Hence by the definition of the order of the anti L-fuzzy Msubgroup of the

M-group $\mathrm{G}$, we have

$\mathrm{O}(\mathrm{A}) / \mathrm{O}(\mathrm{G})$.

2.2 Theorem: Let A and B be two L-fuzzy subsets of a Mabelian group $\mathrm{G}$. Then $\mathrm{A}$ and $\mathrm{B}$ are conjugate L-fuzzy subsets of the M-group $\mathrm{G}$ if and only if $\mathrm{A}=\mathrm{B}$.

Proof: Let A and B be conjugate L-fuzzy subsets of Mgroup $G$, then for some $y \in G$, we have, $\mu_{A}(x)=\mu_{B}\left(y^{-1} x y\right)$, for every $\mathrm{x} \in \mathrm{G}$

$$
\begin{aligned}
& =\mu_{\mathrm{B}}\left(\mathrm{yy}^{-1} \mathrm{x}\right), \\
& \text { since } \mathrm{G} \text { is a } \mathrm{M} \text {-abelian group } \\
& =\mu_{\mathrm{B}}(\text { ex })=\mu_{\mathrm{B}}(\mathrm{x}) .
\end{aligned}
$$

Therefore, $\mu_{\mathrm{A}}(\mathrm{x})=\mu_{\mathrm{B}}(\mathrm{x})$.

Hence $\mathrm{A}=\mathrm{B}$.

Conversely, if $\mathrm{A}=\mathrm{B}$, then for the identity element ' $\mathrm{e}$ ' of M-group G

we have, $\mu_{A}(x)=\mu_{B}\left(e^{-1} x e\right)$, for every $x \in G$.

Hence $\mathrm{A}$ and $\mathrm{B}$ are conjugate L-fuzzy subsets of the Mgroup G.

2.3 Theorem: If $\mathrm{A}$ and $\mathrm{B}$ are conjugate L-fuzzy $\mathrm{M}$ subgroups of the M-group $\mathrm{G}$, then $\mathrm{O}(\mathrm{A})=\mathrm{O}(\mathrm{B})$.

Proof: Let A and B be conjugate L-fuzzy M-subgroups of the M-group $\mathrm{G}$.

Now, $\mathrm{O}(\mathrm{A})=$ order of $\left\{\mathrm{x} \in \mathrm{G} / \mu_{\mathrm{A}}(\mathrm{x})=\mu_{\mathrm{A}}(\mathrm{e})\right\}$

$$
\begin{aligned}
& =\operatorname{order} \text { of }\left\{x \in G / \mu_{B}\left(y^{-1} x y\right)\right. \\
& \left.=\mu_{B}\left(y^{-1} \text { ey }\right)\right\} \\
& =\text { order of }\left\{x \in G / \mu_{B}(x)=\mu_{B}(e)\right\} \\
& =O(B) .
\end{aligned}
$$

Hence $\mathrm{O}(\mathrm{A})=\mathrm{O}(\mathrm{B})$.

2.4 Theorem: Let $A$ be an anti L-fuzzy M-subgroup of a M-group $G$, then the pseudo anti L-fuzzy M-coset $(a A)^{p}$ is an anti L-fuzzy M-subgroup of a M-group $\mathrm{G}$, for every $\mathrm{a} \in \mathrm{G}$.

Proof: Let A be an anti L-fuzzy M-subgroup of a M-group G.

For every $\mathrm{x}$ and $\mathrm{y}$ in $\mathrm{G}$, we have,

$$
\begin{aligned}
\left(\left(a \mu_{\mathrm{A}}\right)^{\mathrm{p}}\right)( & \left.\mathrm{mxy} \mathrm{y}^{-1}\right)=\mathrm{p}(\mathrm{a}) \mu_{\mathrm{A}}\left(\mathrm{mxy}^{-1}\right) \\
& \leq \mathrm{p}(\mathrm{a})\left\{\mu_{\mathrm{A}}(\mathrm{x}) \vee \mu_{\mathrm{A}}(\mathrm{y})\right\} \\
& =\left\{\mathrm{p}(\mathrm{a}) \mu_{\mathrm{A}}(\mathrm{x}) \vee \mathrm{p}(\mathrm{a}) \mu_{\mathrm{A}}(\mathrm{y})\right\} \\
& =\left(\left(\mathrm{a} \mu_{\mathrm{A}}\right)^{\mathrm{p}}\right)(\mathrm{x}) \vee\left(\left(\mathrm{a} \mu_{\mathrm{A}}\right)^{\mathrm{p}}\right)(\mathrm{y}) .
\end{aligned}
$$

Therefore, $\left(\left(a \mu_{A}\right)^{p}\right)\left(m x y^{-1}\right) \leq\left(\left(a \mu_{A}\right)^{p}\right)(x) \vee\left(\left(a \mu_{A}\right)^{p}\right)(y)$.
Hence $(\mathrm{aA})^{\mathrm{p}}$ is an anti L-fuzzy M-subgroup of a M-group G.

2.5 Theorem: If A is an anti L-fuzzy M-subgroup of a Mgroup $\mathrm{G}$, then for any $\mathrm{a} \in \mathrm{G}$, the anti L-fuzzy M-middle coset $\mathrm{aAa}^{-1}$ of $\mathrm{G}$ is also an anti L-fuzzy M-subgroup of $\mathrm{G}$.

Proof: Let A be an anti L-fuzzy M-subgroup of a M-group $\mathrm{G}$ and $\mathrm{a} \in \mathrm{G}$.

To prove $\mathrm{aAa}^{-1}=\left(\mathrm{x}, \mathrm{a} \mu_{\mathrm{A}} \mathrm{a}^{-1}, a v_{\mathrm{A}} \mathrm{a}^{-1}\right)$ is an anti L-fuzzy Msubgroup of a M-group $\mathrm{G}$.

Let $\mathrm{x}$ and $\mathrm{y}$ in $\mathrm{G}$. Then,

$\left(\mathrm{a} \mu_{\mathrm{A}} \mathrm{a}^{-1}\right)\left(m x y^{-1}\right)=\mu_{\mathrm{A}}\left(\mathrm{ma}^{-1} \mathrm{xy}^{-1} \mathrm{a}\right)$, by the definition

$$
=\mu_{\mathrm{A}}\left(\mathrm{ma}^{-1} \mathrm{xaa}^{-1} \mathrm{y}^{-1} \mathrm{a}\right)
$$$$
=\mu_{A}\left(\mathrm{~m}\left(\mathrm{a}^{-1} \mathrm{xa}\right)\left(\mathrm{a}^{-1} \mathrm{ya}\right)^{-1}\right)
$$$$
\leq \mu_{\mathrm{A}}\left(\mathrm{a}^{-1} \mathrm{xa}\right) \vee \mu_{\mathrm{A}}\left(\left(\mathrm{a}^{-1} \mathrm{ya}\right)^{-1}\right)
$$

$\leq \mu_{A}\left(a^{-1} x a\right) \vee \mu_{A}\left(a^{-1}\right.$ ya $)$, since $A$ is an ALFMSG of $G$ $=\left(a \mu_{\mathrm{A}} \mathrm{a}^{-1}\right)(\mathrm{x}) \vee\left(\mathrm{a} \mu_{\mathrm{A}} \mathrm{a}^{-1}\right)(\mathrm{y})$.

Therefore, $\left(a \mu_{\mathrm{A}} \mathrm{a}^{-1}\right)\left(m x y^{-1}\right) \leq\left(a \mu_{\mathrm{A}} \mathrm{a}^{-1}\right)(\mathrm{x}) \vee\left(a \mu_{\mathrm{A}} \mathrm{a}^{-1}\right)(\mathrm{y})$. Hence $\mathrm{aAa}^{-1}$ is an anti L-fuzzy M-subgroup of a M-group $\mathrm{G}$.

2.6 Theorem: Let A be an anti L-fuzzy M-subgroup of a M-group $\mathrm{G}$ and $\mathrm{aAa}^{-1}$ be an anti L-fuzzy M-middle coset of $\mathrm{G}$, then $\mathrm{O}\left(\mathrm{aAa}^{-1}\right)=\mathrm{O}(\mathrm{A})$, for any $\mathrm{a} \in \mathrm{G}$.

Proof: Let A be an anti L-fuzzy M-subgroup of a M-group $\mathrm{G}$ and $\mathrm{a} \in \mathrm{G}$.

By Theorem 2.5, the anti L-fuzzy M-middle coset $\mathrm{aAa}^{-1}$ is an anti L-fuzzy M-subgroup of $\mathrm{G}$. Further by the definition of an anti L-fuzzy M-middle coset of a M-group $\mathrm{G}$, we have,

$\left(a \mu_{A} a^{-1}\right)(x)=\mu_{A}\left(a^{-1} x a\right)$, for every $x$ in $G$.

Hence for any $a \in G, A$ and $a A a^{-1}$ are conjugate anti L-fuzzy M-subgroups of a M-group $\mathrm{G}$ as there exists $a \in G$ such that $\quad\left(a \mu_{A} a^{-1}\right)(x)=\mu_{A}\left(a^{-1} x a\right)$, for every $\mathrm{x} \in \mathrm{G}$.

By Theorem 2.3, $\mathrm{O}\left(\mathrm{aAa}^{-1}\right)=\mathrm{O}(\mathrm{A}), \quad$ for any $\mathrm{a} \in \mathrm{G}$.

2.7 Theorem: Let A be an anti L-fuzzy M-subgroup of a M-group $\mathrm{G}$ and B be a L-fuzzy subset of a M-group G. If A and $\mathrm{B}$ are conjugate L-fuzzy subsets of the M-group $\mathrm{G}$, then B is an anti L-fuzzy M-subgroup of a M-group G.

Proof: Let A be an anti L-fuzzy M-subgroup of a M-group $\mathrm{G}$ and $\mathrm{B}$ be a L-fuzzy subset of a M-group G. And, let A and $\mathrm{B}$ be conjugate L-fuzzy subsets of the M-group $\mathrm{G}$.

To prove $\mathrm{B}$ is an anti L-fuzzy M-subgroup of the M-group $\mathrm{G}$.

Let $\mathrm{x}$ and $\mathrm{y}$ in $\mathrm{G}$ and $\mathrm{m}$ in $\mathrm{M}$. Then $\mathrm{mxy}^{-1} \in \mathrm{G}$.

Now, $\mu_{\mathrm{B}}\left(\mathrm{mxy}^{-1}\right)=\mu_{\mathrm{A}}\left(\mathrm{mg}^{-1} \mathrm{xy}^{-1} \mathrm{~g}\right)$, for some $\mathrm{g} \in \mathrm{G}$

$$
\begin{aligned}
& =\mu_{\mathrm{A}}\left(\mathrm{mg}^{-1} \mathrm{xgg}^{-1} \mathrm{y}^{-1} \mathrm{~g}\right) \\
& =\mu_{\mathrm{A}}\left(\left(\mathrm{mg}^{-1} \mathrm{xg}\right)\left(\mathrm{g}^{-1} \mathrm{yg}\right)^{-1}\right) \\
& \leq \mu_{\mathrm{A}}\left(\mathrm{g}^{-1} \mathrm{xg}\right) \vee \mu_{\mathrm{A}}\left(\left(\mathrm{g}^{-1} \mathrm{yg}\right)^{-1}\right) \\
& \leq \mu_{\mathrm{A}}\left(\mathrm{g}^{-1} \mathrm{xg}\right) \vee \mu_{\mathrm{A}}\left(\mathrm{g}^{-1} \mathrm{yg}\right), \\
& \text { since A is an ALFMSG of } \mathrm{G}
\end{aligned}
$$$$
\leq \mu_{\mathrm{B}}(\mathrm{x}) \vee \mu_{\mathrm{B}}(\mathrm{y}) \text {, since } \mathrm{A} \text { and } \mathrm{B} \text { are }
$$

conjugate L-fuzzy subsets of the M-group $\mathrm{G}$.

Therefore, $\mu_{\mathrm{B}}\left(\mathrm{mxy}^{-1}\right) \leq \mu_{\mathrm{B}}(\mathrm{x}) \vee \mu_{\mathrm{B}}(\mathrm{y})$. 
Hence B is an anti L-fuzzy M-subgroup of the M-group G.

2.8 Theorem: Let $A$ be an anti L-fuzzy M-subgroup of a M-group $G$.Then $\mathrm{aA}_{\mathrm{t}}=(\mathrm{aA})_{\mathrm{t}}$, for every $\mathrm{a} \in \mathrm{G}$ and $\mathrm{t} \in \mathrm{L}$.

Proof: Let A be an anti L-fuzzy M-subgroup of a M-group $\mathrm{G}$ and let $\mathrm{x} \in \mathrm{G}$.

Now, $\mathrm{x} \in(\mathrm{aA})_{\mathrm{t}} \Leftrightarrow\left(\mathrm{a} \mu_{\mathrm{A}}\right)(\mathrm{x}) \leq \mathrm{t}$

$$
\begin{aligned}
& \Leftrightarrow \mu_{\mathrm{A}}\left(\mathrm{a}^{-1} \mathrm{x}\right) \leq \mathrm{t} \\
& \Leftrightarrow \mathrm{a}^{-1} \mathrm{x} \in \mathrm{A}_{\mathrm{t}} \\
& \Leftrightarrow \mathrm{x} \in \mathrm{aA}_{\mathrm{t}} .
\end{aligned}
$$

Therefore, $\quad \mathrm{aA}_{\mathrm{t}}=(\mathrm{aA})_{\mathrm{t}}$, for every $\mathrm{x} \in \mathrm{G}$.

2.9 Theorem: Let A be an anti L-fuzzy M-subgroup of a M-group $\mathrm{G}$. Then $\mathrm{xA}=\mathrm{yA}$, for $\mathrm{x}$ and $\mathrm{y}$ in $\mathrm{G}$ if and only if $\mu_{\mathrm{A}}\left(\mathrm{x}^{-1} \mathrm{y}\right)=\mu_{\mathrm{A}}\left(\mathrm{y}^{-1} \mathrm{x}\right)=\mu_{\mathrm{A}}(\mathrm{e})$.

Proof: Let A be an anti L-fuzzy M-subgroup of a M-group G.

Let $\mathrm{xA}=\mathrm{yA}$, for $\mathrm{x}$ and $\mathrm{y}$ in $\mathrm{G}$.

Then, $x \mu_{A}(x)=y \mu_{A}(x)$ and $x \mu_{A}(y)=y \mu_{A}(y)$,

which implies that, $\mu_{\mathrm{A}}\left(\mathrm{x}^{-1} \mathrm{x}\right)=\mu_{\mathrm{A}}\left(\mathrm{y}^{-1} \mathrm{x}\right)$ and $\mu_{\mathrm{A}}\left(\mathrm{x}^{-1} \mathrm{y}\right)=$ $\mu_{\mathrm{A}}\left(\mathrm{y}^{-1} \mathrm{y}\right)$.

Hence $\mu_{\mathrm{A}}(\mathrm{e})=\mu_{\mathrm{A}}\left(\mathrm{y}^{-1} \mathrm{x}\right)$ and $\mu_{\mathrm{A}}\left(\mathrm{x}^{-1} \mathrm{y}\right)=\mu_{\mathrm{A}}(\mathrm{e})$

Therefore, $\mu_{\mathrm{A}}\left(\mathrm{x}^{-1} \mathrm{y}\right)=\mu_{\mathrm{A}}\left(\mathrm{y}^{-1} \mathrm{x}\right)=\mu_{\mathrm{A}}(\mathrm{e})$.

Conversely, let $\mu_{\mathrm{A}}\left(\mathrm{x}^{-1} \mathrm{y}\right)=\mu_{\mathrm{A}}\left(\mathrm{y}^{-1} \mathrm{x}\right)=\mu_{\mathrm{A}}(\mathrm{e})$, for $\mathrm{x}$ and $\mathrm{y}$ in G.

For every $\mathrm{g}$ in $\mathrm{G}$ and we have,

$$
\begin{aligned}
\mathrm{x} \mu_{\mathrm{A}}(\mathrm{g}) & =\mu_{\mathrm{A}}\left(\mathrm{x}^{-1} \mathrm{~g}\right) \\
& =\mu_{\mathrm{A}}\left(\mathrm{x}^{-1} \mathrm{yy} \mathrm{y}^{-1} \mathrm{~g}\right) \\
& \leq \mu_{\mathrm{A}}\left(\mathrm{x}^{-1} \mathrm{y}\right) \vee \mu_{\mathrm{A}}\left(\mathrm{y}^{-1} \mathrm{~g}\right) \\
& \leq \mu_{\mathrm{A}}(\mathrm{e}) \vee \mu_{\mathrm{A}}\left(\mathrm{y}^{-1} \mathrm{~g}\right) \\
& =\mu_{\mathrm{A}}\left(\mathrm{y}^{-1} \mathrm{~g}\right) \\
& =\mathrm{y} \mu_{\mathrm{A}}(\mathrm{g}) .
\end{aligned}
$$

Therefore, $x \mu_{\mathrm{A}}(\mathrm{g}) \leq \mathrm{y} \mu_{\mathrm{A}}(\mathrm{g})$

And, $\quad \mathrm{y} \mu_{\mathrm{A}}(\mathrm{g})=\mu_{\mathrm{A}}\left(\mathrm{y}^{-1} \mathrm{~g}\right)$

$$
\begin{aligned}
& =\mu_{\mathrm{A}}\left(\mathrm{y}^{-1} \mathrm{xx}^{-1} \mathrm{~g}\right) \\
& \leq \mu_{\mathrm{A}}\left(\mathrm{y}^{-1} \mathrm{x}\right) \vee \mu_{\mathrm{A}}\left(\mathrm{x}^{-1} \mathrm{~g}\right) \\
& \leq \mu_{\mathrm{A}}(\mathrm{e}) \vee \mu_{\mathrm{A}}\left(\mathrm{x}^{-1} \mathrm{~g}\right) \\
& =\mu_{\mathrm{A}}\left(\mathrm{x}^{-1} \mathrm{~g}\right) \\
& =\mathrm{x} \mu_{\mathrm{A}}(\mathrm{g}) .
\end{aligned}
$$

Therefore, $y \mu_{\mathrm{A}}(\mathrm{g}) \leq \mathrm{x} \mu_{\mathrm{A}}(\mathrm{g})$

From (1) and (2) we get,

$\mathrm{x} \mu_{\mathrm{A}}(\mathrm{g})=\mathrm{y} \mu_{\mathrm{A}}(\mathrm{g})$

we get, $\mathrm{xA}=\mathrm{Ya}$.

2.10 Theorem: Let A be an anti L-fuzzy M-subgroup of a M-group $\mathrm{G}$ and $\mathrm{xA}=\mathrm{yA}$, for $\mathrm{x}$ and $\mathrm{y}$ in $\mathrm{G}$. Then $\mu_{\mathrm{A}}(\mathrm{x})=$ $\mu_{\mathrm{A}}(\mathrm{y})$.

Proof: Let A be an anti L-fuzzy M-subgroup of a M-group $\mathrm{G}$ and $\mathrm{xA}=\mathrm{yA}$, for $\mathrm{x}$ and $\mathrm{y}$ in $\mathrm{G}$.

$$
\text { Now, } \quad \begin{aligned}
\mu_{\mathrm{A}}(\mathrm{x}) & =\mu_{\mathrm{A}}\left(\mathrm{yy}^{-1} \mathrm{x}\right) \\
& \leq \mu_{\mathrm{A}}(\mathrm{y}) \vee \mu_{\mathrm{A}}\left(\mathrm{y}^{-1} \mathrm{x}\right) \\
& =\mu_{\mathrm{A}}(\mathrm{y}) \vee \mu_{\mathrm{A}}(\mathrm{e}), \text { by Theorem }
\end{aligned}
$$

Therefore, $\mu_{\mathrm{A}}(\mathrm{x}) \leq \mu_{\mathrm{A}}(\mathrm{y})$------------ (1).

And, $\quad \mu_{\mathrm{A}}(\mathrm{y})=\mu_{\mathrm{A}}\left(\mathrm{xx}^{-1} \mathrm{y}\right)$ $\leq \mu_{\mathrm{A}}(\mathrm{x}) \vee \mu_{\mathrm{A}}\left(\mathrm{x}^{-1} \mathrm{y}\right)$
$=\mu_{\mathrm{A}}(\mathrm{x}) \vee \mu_{\mathrm{A}}(\mathrm{e})$,

by Theorem 2.9

$$
=\mu_{\mathrm{A}}(\mathrm{x}) \text {. }
$$

Therefore, $\mu_{\mathrm{A}}(\mathrm{y}) \leq \mu_{\mathrm{A}}(\mathrm{x})$-------- (2).

From (1) and (2) we get, $\mu_{\mathrm{A}}(\mathrm{x})=\mu_{\mathrm{A}}(\mathrm{y})$.

2.11 Theorem: Let $A$ be an anti L-fuzzy M-subgroup of a M-group $\mathrm{G}$ and $\mathrm{xA}_{\mathrm{t}}=\mathrm{yA}_{\mathrm{t}}$, for $x$ and $y \in G$ $-A_{t}, t \in L$. Then $\mu_{A}(x)=\mu_{A}(y)$.

Proof: Let A be an anti L-fuzzy M-subgroup of a M-group $G$ and $x_{t}=y A_{t}$, for $x$ and $y \in G-A_{t}, t \in L$.

But $\mathrm{y}^{-1} \mathrm{x}$ and $\mathrm{x}^{-1} \mathrm{y} \in \mathrm{A}_{\mathrm{t}}$.

Now, $\mu_{\mathrm{A}}(\mathrm{x})=\mu_{\mathrm{A}}\left(\mathrm{yy}^{-1} \mathrm{x}\right)$

$$
\begin{aligned}
& \leq \mu_{\mathrm{A}}(\mathrm{y}) \vee \mu_{\mathrm{A}}\left(\mathrm{y}^{-1} \mathrm{x}\right) \\
= & \mu_{\mathrm{A}}(\mathrm{y}) .
\end{aligned}
$$

Therefore, $\mu_{\mathrm{A}}(\mathrm{x}) \leq \mu_{\mathrm{A}}(\mathrm{y})$--------------- (1).

And, $\quad \mu_{\mathrm{A}}(\mathrm{y})=\mu_{\mathrm{A}}\left(\mathrm{xx}^{-1} \mathrm{y}\right)$

$$
\leq \mu_{\mathrm{A}}(\mathrm{x}) \vee \mu_{\mathrm{A}}\left(\mathrm{x}^{-1} \mathrm{y}\right)
$$$$
=\mu_{\mathrm{A}}(\mathrm{x})
$$

Therefore, $\quad \mu_{\mathrm{A}}(\mathrm{y}) \leq \mu_{\mathrm{A}}(\mathrm{x})$------------- (2)

From (1) and (2) we get, $\mu_{\mathrm{A}}(\mathrm{x})=\mu_{\mathrm{A}}(\mathrm{y})$.

2.12 Theorem: If $A$ is an anti L-fuzzy normal M-subgroup of a M-group $G$, then the set $G / A=\{x A: x \in G\}$ is a $M$ group with the operation $(x A)(y A)=(x y) A$.

Proof: Let $\mathrm{x}$ and $\mathrm{y} \in \mathrm{G}, \mathrm{xA}$ and $\mathrm{yA} \in \mathrm{G} / \mathrm{A}$.

Clearly, $\mathrm{y}^{-1} \in \mathrm{G}$.

Therefore, $\mathrm{y}^{-1} \mathrm{~A} \in \mathrm{G} / \mathrm{A}$.

Now, $(x A)\left(y^{-1} A\right)=\left(x y^{-1}\right) A \in G / A$. Hence $\mathrm{G} / \mathrm{A}$ is a M-group.

2.13 Theorem: Let $\mathrm{f}: \mathrm{G} \rightarrow \mathrm{H}$ be a homomorphism of $\mathrm{M}$ groups and let $\mathrm{B} \quad$ be an anti L-fuzzy normal M-subgroup of $\mathrm{H}$ and $\mathrm{A}=\mathrm{f}^{-1}(\mathrm{~B})$. Then $\varphi: \mathrm{G} / \mathrm{A} \rightarrow$ $\mathrm{H} / \mathrm{B}$ such that $\varphi(\mathrm{xA})=\mathrm{f}(\mathrm{x}) \mathrm{B}$, for every $\mathrm{x} \in \mathrm{G}$, is an isomorphism of M-group.

Proof: Clearly $\varphi$ is onto.

Let $x A$ and $y A \in G / A$.

Now,$\varphi(\mathrm{xA})=\varphi(\mathrm{yA})$,

which implies that, $f(x) B=f(y) B$,

By Theorem 2.9,

$\mu_{\mathrm{B}}\left(\mathrm{f}(\mathrm{x})^{-1} \mathrm{f}(\mathrm{y})\right)=\mu_{\mathrm{B}}\left(\mathrm{f}(\mathrm{y})^{-1} \mathrm{f}(\mathrm{x})\right)=\mu_{\mathrm{B}}(\mathrm{f}(\mathrm{e}))$,

which implies that

$\mu_{\mathrm{B}}\left(\mathrm{f}\left(\mathrm{x}^{-1}\right) \mathrm{f}(\mathrm{y})\right)=\mu_{\mathrm{B}}\left(\mathrm{f}\left(\mathrm{y}^{-1}\right) \mathrm{f}(\mathrm{x})\right)=\mu_{\mathrm{B}}(\mathrm{f}(\mathrm{e}))$,

which implies that

$\mu_{\mathrm{B}}\left(\mathrm{f}\left(\mathrm{x}^{-1} \mathrm{y}\right)\right)=\mu_{\mathrm{B}}\left(\mathrm{f}\left(\mathrm{y}^{-1} \mathrm{x}\right)\right)=\mu_{\mathrm{B}}(\mathrm{f}(\mathrm{e}))$, since $\mathrm{f}$ is a homomorphism.

Using Theorem 2.9, we get, $\mathrm{xA}=\mathrm{yA}$.

Hence $\varphi$ is one-one .

$$
\text { Now, } \begin{aligned}
\varphi((\mathrm{xA})(\mathrm{yA})) & =\varphi((\mathrm{xy}) \mathrm{A})) \\
& =\mathrm{f}(\mathrm{xy}) \mathrm{B} \\
& =(\mathrm{f}(\mathrm{x}) \mathrm{f}(\mathrm{y})) \mathrm{B},
\end{aligned}
$$

since $\mathrm{f}$ is a homomorphism

$$
=(\mathrm{f}(\mathrm{x}) \mathrm{B})(\mathrm{f}(\mathrm{y}) \mathrm{B})
$$

$=\varphi(\mathrm{xA}) \varphi(\mathrm{yA})$.

Therefore, $\varphi((\mathrm{xA})(\mathrm{yA}))=\varphi(\mathrm{xA}) \varphi(\mathrm{yA})$.

Hence $\varphi$ is an isomorphism. 
2.14 Theorem: Let $\mathrm{f}: \mathrm{G} \rightarrow \mathrm{H}$ be an anti-homomorphism of M-groups and let B be an anti L-fuzzy normal M-subgroup of $\mathrm{H}$ and $\mathrm{A}=\mathrm{f}^{-1}(\mathrm{~B})$. Then $\varphi: \mathrm{G} / \mathrm{A} \rightarrow$ $H$ / B such that $\varphi(x a)=f(x) B$, for every $x \in G$, is an antiisomorphism of M-group.

Proof: Clearly $\varphi$ is onto. Let $x A$ and $y A \in G$ / A.

Now, $\varphi(\mathrm{xA})=\varphi(\mathrm{yA})$,

which implies that $f(x) B=f(y) B$,

By Theorem 2.9

$\mu_{\mathrm{B}}\left(\mathrm{f}(\mathrm{x})^{-1} \mathrm{f}(\mathrm{y})\right)=\mu_{\mathrm{B}}\left(\mathrm{f}(\mathrm{y})^{-1} \mathrm{f}(\mathrm{x})\right)=\mu_{\mathrm{B}}(\mathrm{f}(\mathrm{e}))$,

which implies that

$\mu_{\mathrm{B}}\left(\mathrm{f}\left(\mathrm{x}^{-1}\right) \mathrm{f}(\mathrm{y})\right)=\mu_{\mathrm{B}}\left(\mathrm{f}\left(\mathrm{y}^{-1}\right) \mathrm{f}(\mathrm{x})\right)=\mu_{\mathrm{B}}(\mathrm{f}(\mathrm{e}))$,

which implies that

$\mu_{\mathrm{B}}\left(\mathrm{f}\left(\mathrm{yx}^{-1}\right)\right)=\mu_{\mathrm{B}}\left(\mathrm{f}\left(\mathrm{xy}^{-1}\right)\right)=\mu_{\mathrm{B}}(\mathrm{f}(\mathrm{e}))$,

since $\mathrm{f}$ is an anti-homomorphism.

Using Theorem 2.9, we get, $\mathrm{xA}=\mathrm{yA}$.

Hence $\varphi$ is one-one.

Now, $\varphi((\mathrm{xA})(\mathrm{yA}))=\varphi((\mathrm{xy}) \mathrm{A}))$

$$
=\mathrm{f}(\mathrm{xy}) \mathrm{B}
$$

$=(\mathrm{f}(\mathrm{y}) \mathrm{f}(\mathrm{x})) \mathrm{B}$, since $\mathrm{f}$ is an anti-

homomorphism

$$
\begin{aligned}
& =(\mathrm{f}(\mathrm{y}) \mathrm{B})(\mathrm{f}(\mathrm{x}) \mathrm{B}) \\
& =\varphi(\mathrm{yA}) \varphi(\mathrm{xA}) .
\end{aligned}
$$

Therefore, $\quad \varphi((\mathrm{xA})(\mathrm{yA}))=\varphi(\mathrm{yA}) \varphi(\mathrm{xa})$.

Hence $\varphi$ is an anti-isomorphism.

In the following proposition $\circ$ is the composition operation of functions :

2.15 Theorem: Let A be an anti L-fuzzy M-subgroup of a $\mathrm{M}$-group $\mathrm{H}$ and $\mathrm{f}$ is an isomorphism from a M-group $\mathrm{G}$ onto $\mathrm{H}$. Then we have the following:

(i) If $\mathrm{A}$ is a generalized characteristic anti L-fuzzy M-subgroup (GCALFMSG) of $\mathrm{H}$, then $\mathrm{A} \circ \mathrm{f}$ is a generalized characteristic anti L-fuzzy Msubgroup of $\mathrm{G}$.

(ii) If $\mathrm{A}$ is a generalized characteristic anti L-fuzzy M-subgroup (GCALFMSG) and $\mathrm{f}$ is an automorphism on $\mathrm{G}$, then $\mathrm{A} \circ \mathrm{f}=\mathrm{A}$.

Proof: Let A be a generalized characteristic anti L-fuzzy M-subgroup (GCFALMSG) of H.

We know that,"Let A be an anti L-fuzzy M-subgroup of a M-group $\mathrm{H}$ and $\mathrm{f}$ is an isomorphism from a M-group $\mathrm{G}$ onto $\mathrm{H}$. Then $\mathrm{A} \circ \mathrm{f}$ is an anti L-fuzzy M-subgroup of a Mgroup G."

Hence $A \circ f$ is an anti L-fuzzy M-subgroup of G.

Let $x$ and $y \in G$ and $O(x)=O(y)$.

Then we have, $\left(\mu_{\mathrm{A}}\right.$ 。f $)(\mathrm{x})=\mu_{\mathrm{A}}(\mathrm{f}(\mathrm{x}))$

$$
=\mu_{\mathrm{A}}(\mathrm{f}(\mathrm{y})) \text {, }
$$

as $\mathrm{O}(\mathrm{f}(\mathrm{x}))=\mathrm{O}(\mathrm{f}(\mathrm{y}))$

isomorphism,

$$
=\left(\mu_{\mathrm{A}} \circ \mathrm{f}\right)(\mathrm{y}) \text {, as } \mathrm{f} \text { is an }
$$

which implies that $\left(\mu_{\mathrm{A}}^{\circ} \circ\right)(\mathrm{x})=\left(\mu_{\mathrm{A}} \circ \mathrm{f}\right)(\mathrm{y})$.

Therefore, $A \circ f$ is a generalized characteristic anti L-fuzzy M-subgroup of $\mathrm{G}$.

Thus (i) is proved.
(ii)Clear.

2.16 Theorem: Let A be an anti L-fuzzy M-subgroup of a $\mathrm{M}$-group $\mathrm{H}$ and $\mathrm{f}$ is an anti-isomorphism from a $\mathrm{M}$-group $\mathrm{G}$ onto $\mathrm{H}$. Then we have the following:

(i) If $\mathrm{A}$ is a generalized characteristic anti L-fuzzy M-subgroup (GCALFMSG) of $\mathrm{H}$, then $\mathrm{A} \circ \mathrm{f}$ is a generalized characteristic anti L-fuzzy Msubgroup of $\mathrm{G}$.

(ii) If $\mathrm{A}$ is a generalized characteristic anti L-fuzzy M-subgroup (GCALFMSG) and $\mathrm{f}$ is an antiautomorphism on $\mathrm{G}$, then $\mathrm{A} \circ \mathrm{f}=\mathrm{A}$.

Proof: Let A be a generalized characteristic anti L-fuzzy M-subgroup (GCALFMSG) of $\mathrm{H}$.

We know that, "Let A be an anti L-fuzzy M-subgroup of a $\mathrm{M}$-group $\mathrm{H}$ and $\mathrm{f}$ is an antiisomorphism from a M-group $\mathrm{G}$ onto $\mathrm{H}$. Then $\mathrm{A} \circ \mathrm{f}$ is an anti L-fuzzy M-subgroup of a M-group G."

Hence A॰f is an anti L-fuzzy M-subgroup of G.

Let $\mathrm{x}$ and $\mathrm{y} \in \mathrm{G}$ and $\mathrm{O}(\mathrm{x})=\mathrm{O}(\mathrm{y})$.

Then we have, $\left(\mu_{\mathrm{A}} \circ \mathrm{f}\right)(\mathrm{x})=\mu_{\mathrm{A}}(\mathrm{f}(\mathrm{x}))$

$$
\begin{aligned}
& =\mu_{\mathrm{A}}(\mathrm{f}(\mathrm{y})) \text {, as } \mathrm{O}(\mathrm{f}(\mathrm{x}))=\mathrm{O}(\mathrm{f}(\mathrm{y})) \\
& =\left(\mu_{\mathrm{A}} \circ \mathrm{f}\right)(\mathrm{y}), \\
& \quad \text { as } \mathrm{f} \text { is an anti-isomorphism, }
\end{aligned}
$$

which implies that $\left(\mu_{\mathrm{A}} \circ \mathrm{f}\right)(\mathrm{x})=\left(\mu_{\mathrm{A}} \circ \mathrm{f}\right)(\mathrm{y})$.

Therefore, $\mathrm{A} \circ \mathrm{f}$ is a generalized characteristic anti L-fuzzy M-subgroup of G.

$$
\text { Thus (i) is proved. }
$$

$$
\text { (ii)Clear. }
$$

\section{REFERENCES}

[1] Azriel Rosenfeld, Fuzzy Groups, Journal of mathematical analysis and

applications 35, (1971) 512-51.

[2] R. Biswas, Fuzzy subgroups and anti-fuzzy subgroups, Fuzzy Sets and Systems 35

(1990), 121-124.

[3] J.A. Goguen, L-fuzzy sets, J. Math. Anal. Appl.18(1967),145-179.

[4] Mohamed Asaad, Groups and Fuzzy Subgroups, Fuzzy Sets and Systems 39(1991)323-328.

[5] Prabir Bhattacharya, Fuzzy subgroups: Some characterizations, J. Math. Anal. Appl. 128 (1981) 241-252. [6] N.Palaniappan, R.Muthuraj, The homomorphism, Antihomomorphism of a fuzzy and an anti-fuzzy group, Varahmihir Journal of mathematical Sciences, 4 (2)(2004) 387-399.

[7] N.Palaniappan, S. Naganathan, \& K. Arjunan, A Study on Intuitionistic L-Fuzzy Subgroups, Applied mathematical Sciences, 3 (53) (2009) 2619-2624.

[8] P.Pandiammal, R.Natarajan, N.Palaniappan, Anti Lfuzzy M-subgroups, Antartica Journal of Mathematics, Accepted for publications.

[9] P.Pandiammal, R.Natarajan, N.Palaniappan, A Study on Lower Level subsets of Anti L-fuzzy M-subgroups, Antartica Journal of Mathematics, Accepted for publications.

[10] L.A. Zadeh, Fuzzy sets, Information and control, 8, (1965) 338-353. 